\title{
openheart Fractional flow reserve derived from microcatheters versus standard pressure wires: a stenosis-level meta-analysis
}

\author{
Henry Seligman, ${ }^{1}$ Matthew J Shun-Shin, ${ }^{1}$ Anushkumar Vasireddy, ${ }^{2}$ \\ Christopher Cook, ${ }^{1}$ Yousif Y Ahmad, ${ }^{1}$ James Howard, ${ }^{1}$ Sayan Sen, ${ }^{1}$ \\ Rasha Al-Lamee, ${ }^{1}$ Sukhjinder Nijjer, ${ }^{1}$ Daniel Chamie, ${ }^{3}$ Justin Davies, ${ }^{1}$ Jamil Mayet, ${ }^{1}$ \\ Darrel P Francis, ${ }^{1}$ Ricardo Petraco ${ }^{1}$
}

To cite: Seligman $\mathrm{H}$, Shun-Shin MJ, Vasireddy A, et al. Fractional flow reserve derived from microcatheters versus standard pressure wires: a stenosis-level meta-analysis. Open Heart 2019;6:e000971. doi:10.1136/

openhrt-2018-000971

Received 25 November 2018 Revised 18 December 2018 Accepted 20 January 2019

\section{ABSTRACT}

Aims To determine the agreement between sensortipped microcatheter (MC) and pressure wire (PW)-derived fractional flow reserve (FFR).

Methods and results Studies comparing FFR obtained from MC (FFR ${ }_{\mathrm{MC}}$, Navvus Microcatheter System, ACIST Medical Systems, Eden Prairie, Minnesota, USA) versus standard PW (FFR $\mathrm{PW}_{\mathrm{PW}}$ ) were identified, and a meta-analysis of numerical and categorical agreement was performed. The relative levels of drift and device failure of $\mathrm{MC}$ and PW systems from each study were assessed. Six studies with 440 lesions (413 patients) were included. The mean overall bias between $\mathrm{FFR}_{\mathrm{MC}}$ and $\mathrm{FFR}_{\mathrm{PW}}$ was -0.029 (FFR $_{\mathrm{MC}}$ lower). Bias and variance were greater for lesions with lower FFR ${ }_{\mathrm{PW}}(\mathrm{p}<0.001)$. Using a cut-off of $0.80,18 \%$ of lesions were reclassified by $\mathrm{FFR}_{\mathrm{MC}}$ versus FFR $_{\mathrm{PW}}$ (with 15 $\%$ being false positives). The difference in reported drift between $\mathrm{FFR}_{\mathrm{PW}}$ and $\mathrm{FFR}_{\mathrm{MC}}$ was small. Device failure was more common with MC than PW $(7.1 \%$ vs $2 \%)$.

Conclusion $\mathrm{FFR}_{\mathrm{MC}}$ systematically overestimates lesion severity, with increased bias in more severe lesions. Using $\mathrm{FFR}_{\mathrm{MC}}$ changes revascularisation guidance in approximately one out of every five cases. PW drift was similar between systems. Device failure was higher with MC.

\section{INTRODUCTION}

Fractional flow reserve (FFR) measured by a sensor-equipped microcatheter (MC, Navvus; ACIST Medical Systems, Eden Prairie, Minnesota, USA) has recently been proposed for functional lesion assessment in the catheterisation laboratory. ${ }^{1}$ MC-derived FFR systems $\left(\mathrm{FFR}_{\mathrm{MC}}\right)$ offer potential advantages over standard pressure guidewire (PW) systems $\left(\mathrm{FFR}_{\mathrm{PW}}\right)$. First, because of their relatively small lumen profile (maximum diameter 0.036 inches at sensor level and 0.025 at optic fibre level) it has been suggested that MC do not interfere significantly with stenosis haemodynamics for lesions likely to need FFR assessment. ${ }^{1}$ Accordingly, FFR values across the same coronary stenosis measured

\section{Key messages}

What is already known about this subject?

- A number of studies have been published comparing sensor-tipped microcatheters to pressure wires but the findings of these studies have not been entirely consistent.

What does this study add?

- This is the first study to synthesise the totality of the lesion-level data from these studies and to provide a meta-analysis of agreement between pressure wire fractional flow reserve (FFR) and microcatheter FFR.

How might this impact on clinical practice?

- Clinicians who choose to use this novel device may consider interpreting the measurements differently. They can use the interactive video in the appendix to find out the range of pressure wire FFR values that correspond to a given microcatheter FFR value.

by MC and PW should be numerically equal. Also, because MC are delivered over standard workhorse coronary guidewires, ${ }^{2}$ their use could, in theory, facilitate lesion crossing in complex anatomies. Finally, MC use fibreoptic sensors, which could reduce the incidence of signal drift, a recognised problem with the piezo-electric sensor technology used in most PW. Observational studies have been published comparing the two methods with regards to FFR agreement. ${ }^{13-7}$ While most highlight a systematic bias in the results, more than one study reports a good agreement between the methodologies highlighting the need for further analysis. Therefore, we performed a lesion-level meta-analysis of the totality of the data from all studies which compared $\mathrm{FFR}_{\mathrm{MC}}$ to $\mathrm{FFR}_{\mathrm{PW}}$ to provide the best possible assessment of the level of agreement between the two devices. We further quantified numerical agreement and changes in 


\begin{tabular}{|c|c|c|c|c|}
\hline \multirow{7}{*}{$\begin{array}{l}\text { Fearon } \\
\text { Ali } \\
\text { Menon } \\
\text { Pouillot } \\
\text { Wijntjens } \\
\text { Diletti }\end{array}$} & $\begin{array}{l}\text { Patient } \\
\text { Selection }\end{array}$ & $\begin{array}{l}\text { Index } \\
\text { Test }\end{array}$ & $\begin{array}{l}\text { Reference } \\
\text { Standard }\end{array}$ & $\begin{array}{l}\text { Flow and } \\
\text { Timing }\end{array}$ \\
\hline & L & L & L & L \\
\hline & L & L & L & L \\
\hline & L & L & L & L \\
\hline & L & L & L & L \\
\hline & L & L & L & L \\
\hline & $?$ & $?$ & $?$ & $?$ \\
\hline
\end{tabular}

\begin{tabular}{|c|c|c|c|}
\hline \multirow{6}{*}{$\begin{array}{l}\text { Fearon } \\
\text { Ali } \\
\text { Menon } \\
\text { Pouillot } \\
\text { Wijntjens } \\
\text { Diletti }\end{array}$} & L & L & L \\
\hline & L & L & L \\
\hline & L & L & L \\
\hline & L & L & L \\
\hline & L & L & $\mathrm{L}$ \\
\hline & $?$ & $?$ & $?$ \\
\hline
\end{tabular}

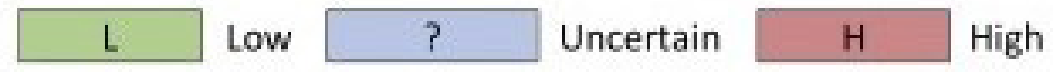

Figure 1 Analysis of risk of bias showing generally low risk of bias in studies where detailed methods were reported.

lesion categorisation and compared the magnitude of sensor drift and reported device failure.

\section{METHODS}

\section{Search strategy}

We performed a systematic review in accordance with guidelines from the Preferred Reporting Items for Systematic Reviews and Meta-Analyses. ${ }^{8}$ We searched Medline and Embase using the broad terms ("Microcatheter" AND "FFR"), ("Navvus" AND "FFR"), ("Navvus" AND "Coronary") from May 2000 week 1 to May 2018 week 1 and we hand searched the reference lists for other studies. Two of the authors (HS and AV) reviewed all the retrieved studies including references. Studies were excluded if they did not investigate the use of the Navvus Microcatheter and compare $\mathrm{FFR}_{\mathrm{MC}}$ and $\mathrm{FFR}_{\mathrm{PW}}$ and show this lesion-level data in scatterplot. Results were limited to publications in peer reviewed journals.

\section{Quality assessment of diagnostic accuracy studies}

Included studies were assessed using the Quality Assessment of Diagnostic Studies tool ${ }^{9}$ which is designed specifically to assess diagnostic accuracy of studies. Risk of bias and applicability of findings are evaluated across four domains: patient selection, index test, reference standard and flow and timing. Risk of bias or concerns regarding applicability are rated as low, high or unclear. This assessment was performed and cross-checked by two authors (HS and AV) and is displayed in figure 1. Generally, we found a low risk of bias although one study ${ }^{1}$ did not report detailed methods.

\section{Data abstraction}

From each study, pairs of FFR values $\left(\mathrm{FFR}_{\mathrm{MC}}\right.$ and $\left.\mathrm{FFR}_{\mathrm{PW}}\right)$ were digitised from scatterplots using bitmap-to-digital software (Matlab, V.6.0; MathWorks). This methodology has been previously described. ${ }^{10}$ Consistency of the method was confirmed by comparing means and SD with those reported in the studies. This method allowed for a more detailed data analysis and display than the simple extraction of mean and standard errors, as most often used in standard meta-analytical approaches. Data on drift and device failure were extracted from each study.

\section{Statistical analysis}

For the baseline and summary data, continuous variables were presented as mean and SD. Categorical variables are presented as percentages. A t-test was used to compare the difference in $\mathrm{FFR}_{\mathrm{MC}}$ and $\mathrm{FFR}_{\mathrm{PW}}$ values. To compare and display $\mathrm{FFR}_{\mathrm{MC}}$ and $\mathrm{FFR}_{\mathrm{PW}}$ values, a Bland-Altman plot of their difference against the mean was produced. ${ }^{11} \mathrm{An}$ overall mean bias and $95 \%$ limits of agreement were calculated. When the Bland-Altman plot demonstrated that the variance and mean bias was not constant throughout the range of values, the regression method of Bland and Altman ${ }^{12}$ was used. Briefly, the differences were regressed against the average to calculate the bias. The resultant limits of agreement were calculated as \pm 1.96 multiplied by the result of a regression of the absolute values of the residuals (from the bias regression) against the mean FFR with the coefficients multiplied by $\sqrt{ }(\varpi / 2)$. Exact binomial tests were used to compare the proportion of false-positive and false-negative rates. To illustrate the 


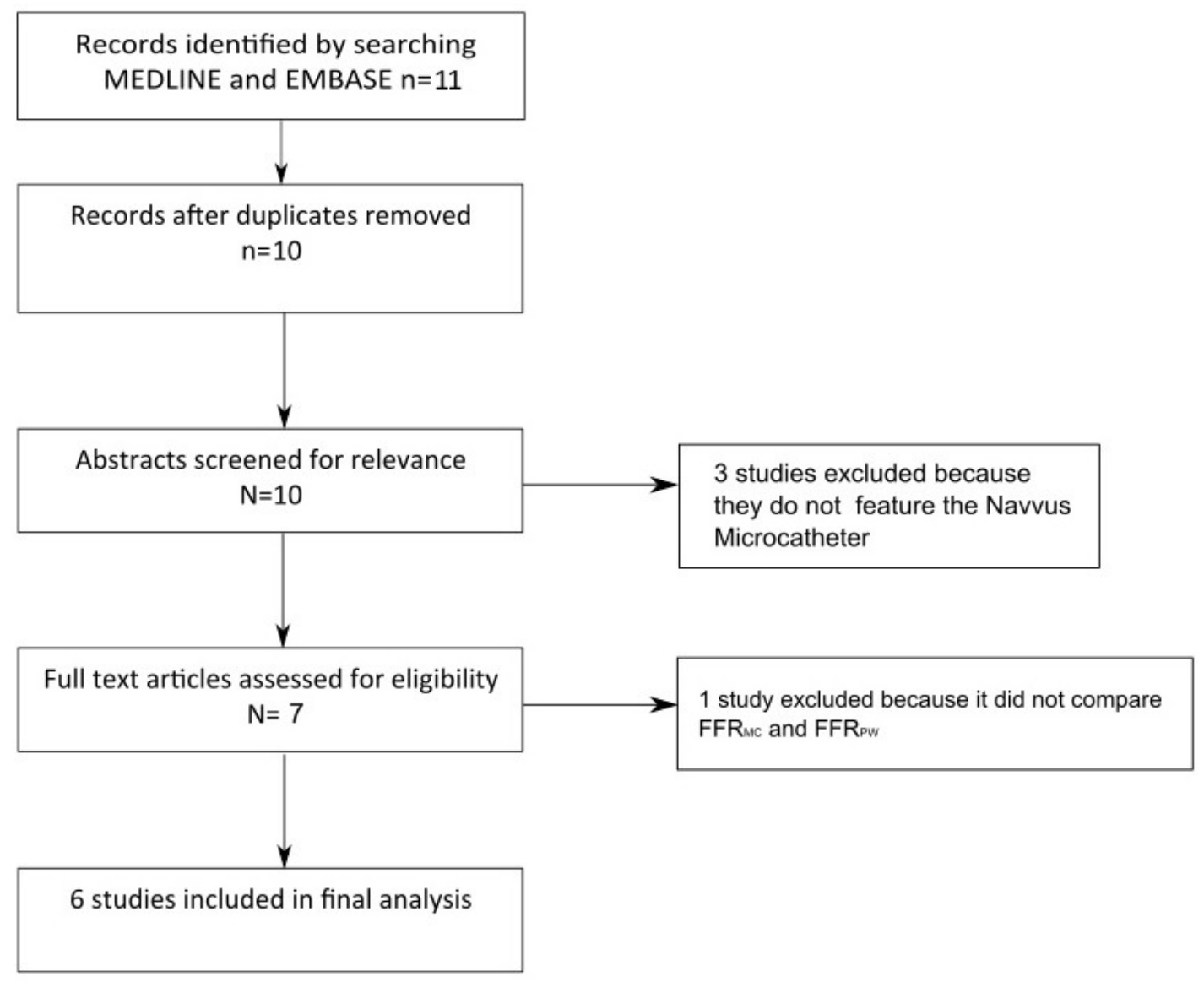

Figure 2 Search strategy flow chart. $\mathrm{FFR}_{\mathrm{MC}}$, microcatheter fractional flow reserve; $\mathrm{FFR}_{\mathrm{PW}}$, pressure wire fractional flow reserve.

range of $\mathrm{FFR}_{\mathrm{PW}}$ values, a physician might expect from an $\mathrm{FFR}_{\mathrm{MC}}$ from the data in the studies, a regression line and 95\% CI for the data were derived using a linear regression with methods similar to Bland-Altman. A fixed-effect meta-analysis was used to compare the differences in drift from summary data provided by the papers. Where the SD of the mean drift wafs absent, it was imputed from mean of other studies. The statistical analysis was performed using the statistical environment ' $R$ ', ${ }^{13}$ with the graphical package 'ggplot2' and the meta-analytical package 'metafor'.

\section{RESULTS}

Six studies, including stenosis-level data from 440 lesions (413 patients), were included in the final analysis (figure 2). ${ }^{13-7}$ All studies compared $\mathrm{FFR}_{\mathrm{MC}}$ to $\mathrm{FFR}_{\mathrm{PW}}$ and provided scatter plots that enabled extraction of raw data. The sample size, means and SD of extracted data points were numerically identical to those reported in each study. The mean age of the patients was 66 years and $80 \%$ were male. Patient characteristics are summarised in table 1. In four studies, $\mathrm{FFR}_{\mathrm{MC}}$ was defined as the FFR measured through the MC sensor. In one study, $\mathrm{FFR}_{\mathrm{MC}}$ was defined as the FFR measured through the PW with the MC across the lesion. In one study, the method was not stated. A larger number of lesions (519) were included in the measurement failure analysis because multiple studies reported device failure data for lesions that were excluded from FFR comparison.

\section{Numerical agreement between $\mathrm{FFR}_{\mathrm{MC}}$ and $\mathrm{FFR}_{\mathrm{PW}}$ values}

Median and IQR for $\mathrm{FFR}_{\mathrm{MC}}$ and $\mathrm{FFR}_{\mathrm{PW}}$ were 0.81 (0.74$0.88)$ and $0.84(0.78-0.89)$, respectively (figure 3$)$. FFR $_{\mathrm{MC}}$ values were significantly lower than $\mathrm{FFR}_{\mathrm{PW}}(-0.02995 \%$ CI -0.034 to $-0.025, \mathrm{p}<0.0001)$.

The mean bias and Bland-Altman 95\% limits of agreement across all lesions were -0.029 (95\% limits of agreement -0.128 to +0.070 ) (figures 4 and 5 ). The mean bias and limits of agreement were dependent on the severity of the lesion $(\mathrm{p}<0.0001$ and $\mathrm{p}<0.0001$, respectively). Lesions with lower FFR demonstrated greater discrepancy between methods, with $\mathrm{FFR}_{\mathrm{MC}}$ yielding increasingly lower values (figure 6 and online supplementary appendix 1). For instance, while a mean FFR of 0.90 was associated with FFR $_{\mathrm{MC}}$ values 0.014 units lower than $\mathrm{FFR}_{\mathrm{PW}}$, a mean FFR of 0.70 was associated with a 0.050 difference. Consistently, $\mathrm{FFR}_{\mathrm{MC}}$ overestimated lesion severity across the spectrum of disease severity. Furthermore, with lower FFR values, the variability of the discrepancy was also higher. At a mean FFR of 0.90 , the SD of the difference between methods was \pm 0.036 , while at a mean FFR of 0.70 , the SD of the difference was \pm 0.053 . The results from the individual trials were comparable (figure 5 ). We provide an online interactive tool from which readers can visualise 
Table 1 Demographic and clinical characteristics of included patients

\begin{tabular}{|c|c|c|c|c|c|c|}
\hline \multirow[b]{2}{*}{ Characteristic } & \multicolumn{6}{|c|}{ Study lead author } \\
\hline & Menon & Fearon & Ali & Diletti & Pouillot & Wijntjens \\
\hline Year & 2015 & 2017 & 2017 & 2015 & 2017 & 2016 \\
\hline Design & $\begin{array}{l}\text { Prospective, } \\
\text { multicentre }\end{array}$ & $\begin{array}{l}\text { Prospective, } \\
\text { multicentre }\end{array}$ & $\begin{array}{l}\text { Prospective, } \\
\text { single centre }\end{array}$ & NR & $\begin{array}{l}\text { Prospective, } \\
\text { single centre }\end{array}$ & $\begin{array}{l}\text { Prospective, single } \\
\text { centre }\end{array}$ \\
\hline Patients, no. & 50 & 169 & 74 & 15 & 77 & 28 \\
\hline Lesions included, no. & 52 & 169 & 88 & 15 & 88 & 28 \\
\hline \multicolumn{7}{|l|}{ Patient baseline } \\
\hline Age, mean, (SD), years & $66(9)$ & $68(9)$ & $64(11)$ & NR & $62(11)$ & $62(12)$ \\
\hline Male no. $(\%)$ & $40(80)$ & $133(79)$ & $54(73)$ & NR & $58(75)$ & $22(79)$ \\
\hline HTN no. (\%) & NR & $140(83)$ & $71(96)$ & NR & $57(74)$ & $15(54)$ \\
\hline Smoking no. (\%) & NR & $23(14)$ & $12(16)$ & NR & $24(32)$ & $6(21)$ \\
\hline Diabetes, no (\%) & NR & $63(37)$ & $53(72)$ & NR & $34(45)$ & $7(25)$ \\
\hline Previous MI, no. (\%) & NR & $53(31)$ & NR & NR & $23(30)$ & $4(14)$ \\
\hline BMI, mean (SD) & NR & $31(7)$ & 28.4 (NR) & NR & $26.5(4.3)$ & NR \\
\hline Stable angina $(\%)$ & NR & $123(74)$ & NR & NR & $12(16)$ & NR \\
\hline Previous PCl, no. (\%) & NR & $75(44)$ & NR & NR & $29(38)$ & $8(29)$ \\
\hline \multicolumn{7}{|l|}{ Vessel characteristics } \\
\hline Left main (\%) & 6 & 2 & 0 & NR & NR & NR \\
\hline Left anterior descending (\%) & 56 & 52 & 49 & NR & NR & NR \\
\hline Left circumflex (\%) & 13 & 18 & 24 & NR & NR & NR \\
\hline Right (\%) & 25 & 26 & 26 & NR & NR & NR \\
\hline Mean diameter stenosis (\%) (SD) & $56(\mathrm{NR})^{*}$ & $47(9)$ & $66(10)$ & NR & $55(9)$ & $52(7)$ \\
\hline Mean RVD (mm) (SD) & NR & $2.8(0.5)$ & $2.5(0.7)$ & NR & $3.05(0.55)$ & $2.64(0.46)$ \\
\hline Mean $\mathrm{FFR}_{\mathrm{PW}}(\mathrm{SD})$ & $0.81(0.11)$ & $0.83(0.1)$ & $0.83(0.09)$ & $0.85(0.08)$ & $0.83(0.07)$ & $0.86(0.06)$ \\
\hline $\mathrm{FFR}_{\mathrm{PW}} 0.6-0.9(\%)$ & 71 & 72 & 77 & 80 & 73 & 82 \\
\hline Comparator pressure wire & St Jude & $\begin{array}{l}\text { St Jude/Philips } \\
\text { Volcano }\end{array}$ & St Jude & NR & St Jude & $\begin{array}{l}\text { Philips Volcano } \\
\text { (Combowire) }\end{array}$ \\
\hline Adenosine administration & Intravenous & Intravenous & Intravenous & NR & Intravenous & Intracoronary \\
\hline
\end{tabular}

${ }^{*}$ Reported as median value.

$\mathrm{BMI}$, body mass index (weight in kilograms divided by height in metres squared); $F_{F R}$, pressure wire fractional flow reserve; HTN, hypertension; MI, myocardial infarction; NR, not recorded; PCl, percutaneous coronary intervention; RVD, reference vessel diameter; mm, millimetres.

the possible range of $\mathrm{FFR}_{\mathrm{PW}}$ values resulting from each possible FFR $_{\mathrm{MC}}$ result.

\section{Lesion reclassification}

Using the clinically established cut-off of FFR $\leq 0.80$, across the 440 lesions assessed, FFR $_{\mathrm{MC}}$ classified more lesions as functionally significant $(47 \%, 207 / 440$ vs $35 \%$, 152/440, $\mathrm{p}<0.01)$. Across all stenoses, 32\% (139/440) had FFR $\leq 0.80$ by both $\mathrm{FFR}_{\mathrm{MC}}$ and $\mathrm{FFR}_{\mathrm{PW}}$ (concordantly positive) and $50 \%(220 / 440)$ had FFR $>0.80$ by both $\mathrm{FFR}_{\mathrm{MC}}$ and $\mathrm{FFR}_{\mathrm{PW}}$ (concordantly negative). Among cases of diagnostic disagreement between methods $(81 / 440$, $18 \%), \mathrm{FFR}_{\mathrm{MC}}$ was more likely to yield 'false positive' (15\%, $68 / 440)$ than 'false negative' (3\% 13/440, $\mathrm{p}<0.0001$, figure 6) results, using $\mathrm{FFR}_{\mathrm{PW}}$ as the reference method. Among the 340 lesions in the intermediate range $\left(\mathrm{FFR}_{\mathrm{PW}}\right.$ from 0.60 to 0.90 ), diagnostic disagreement was higher
(23\%, 77/340), particularly 'false positives' (19\%, 64/340, figure 7 ). Figure 6 is a scatter plot of the combined data from all studies showing regions of lesion reclassification across a diagnostic FFR threshold of 0.80 .

\section{Signal drift}

In all five studies where the method of drift measurement was recorded, drift was measured separately for the PW and MC. Of the four studies that presented a point estimate of signal drift, ${ }^{4-7}$ only one presented individual patient data. ${ }^{4}$ In three of these studies, ${ }^{5-7}$ no clinically significant difference in the mean level of drift between $\mathrm{FFR}_{\mathrm{MC}}$ and $\mathrm{FFR}_{\mathrm{PW}}$ was reported table 2. One study ${ }^{4}$ found a significantly higher mean drift with $\mathrm{FFR}_{\mathrm{PW}}$ than $\mathrm{FFR}_{\mathrm{MC}}$. In this study, the mean drift was strongly driven by three unusually large PW drift values of $0.65,0.40$ and 0.34 (FFR units). 


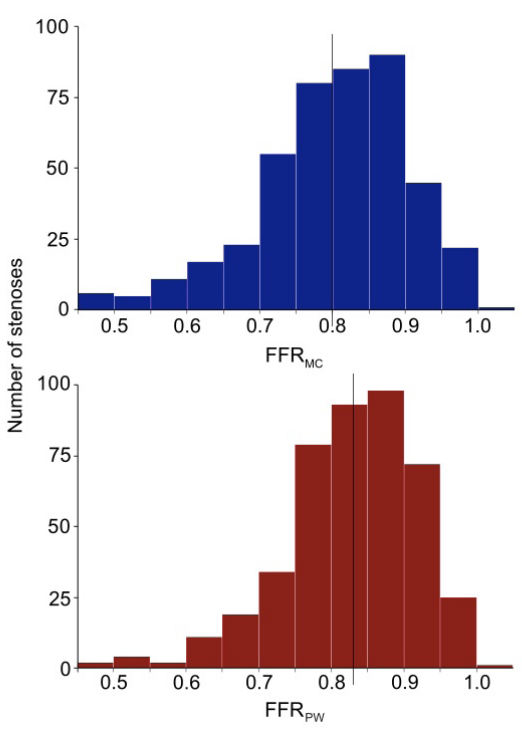

Figure 3 Histograms of pressure wire FFR values for $F F R_{M C}$ and $F F R_{\mathrm{PW}}$. These reveal a typical unimodal distribution with predominantly intermediate FFR values. The black lines indicate median values. $\mathrm{FFR}_{\mathrm{MC}}$, microcatheter fractional flow reserve; $F_{F F}$, pressure wire fractional flow reserve.

\section{Measurement failure}

We defined measurement failure as inability to cross the lesion with the device and record FFR. Device failure reporting was not consistent between studies. One study did not report rates of device failure. From the remaining five studies, the overall mean rate of reported failure was higher for MC than PW (7.1\% and 2\%, respectively). The results are shown in table 3 .

\section{DISCUSSION AND LIMITATIONS}

We performed a lesion-level meta-analysis of 6 studies including 440 coronary stenoses, in which FFR was measured with a MC system (Navvus; ACIST Medical Systems) and compared with PW. We found that (1) MC and PW yield numerically different FFR values for the same stenosis, with evidence of a systematic bias towards lower FFR values with the use of MC; (2) the magnitude of such bias increased with functional lesion severity; (3) as a result of such numerical differences, there was a $18 \%$ rate of disagreement in lesion classification by $\mathrm{FFR}_{\mathrm{MC}}$ and $\mathrm{FFR}_{\mathrm{PW}}$; (4) the incidence of signal drift was similar for PW and MC and (5) device failure was more common with MC.

\section{FFR as a numerical replacement for PW FFR}

Our analysis found that on average, MC overestimate lesion severity by 0.029 FFR units. Therefore, the methodologies cannot be seen as numerically equivalent. The notion of simply adjusting individual $\mathrm{FFR}_{\mathrm{MC}}$ values by removing 0.029 units would not provide a reliable solution in individual cases as the scatter of variation is wide (mean overall difference of -0.029 but $95 \%$ of data ranging from -0.128 to +0.070$)$. Also, bias increased

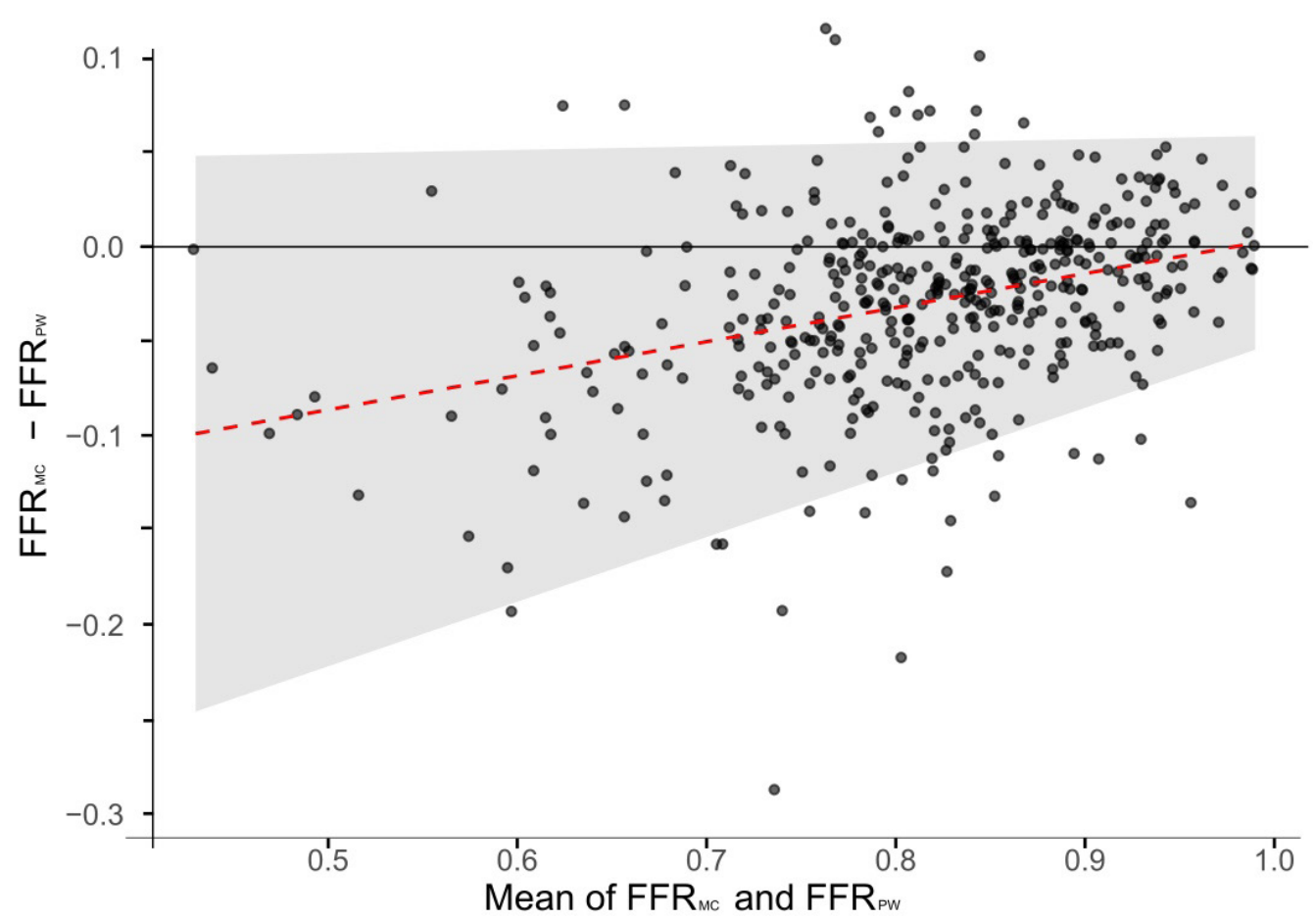

Figure 4 Bland-Altman plot of agreement between microcatheter and pressure wire FFR. The shaded area shows the limits of agreement between the variables. The red dashed line shows the bias calculated by regression. As can be seen the level of bias and variability increase with decreasing mean FFR value. FFR ${ }_{M C}$, microcatheter fractional flow reserve; FFR $\mathrm{PW}_{\mathrm{PW}}$, pressure wire fractional flow reserve. 


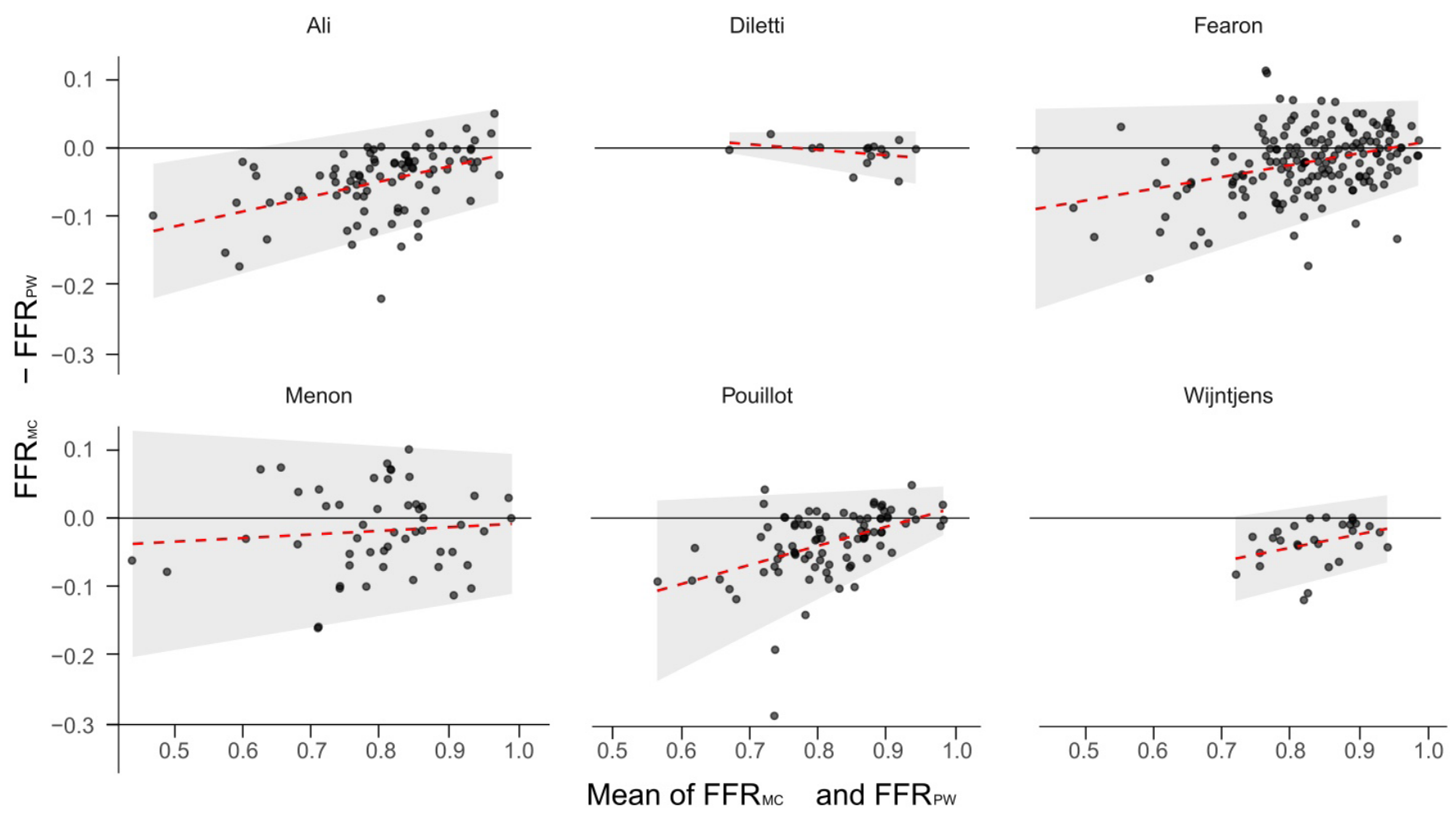

Figure 5 Bland-Altman plots of microcatheter and pressure wire FFR for the individual studies. The overall pattern of increasing bias and variability at lower FFR values is reproduced in all but one small study. $\mathrm{FFR}_{\mathrm{MC}}$, microcatheter fractional flow reserve; $F_{F R}$, pressure wire fractional flow reserve.

and LOA were wider with lower FFR values, for instance reaching -0.050 ( $\mathrm{LOA}-0.153,0.053)$ in stenoses with mean FFR of 0.70 (figure 4).

\section{FFR $_{\mathrm{Mc}}$ often changes lesion classification}

This study shows that the frequency of reclassification of lesions by $\mathrm{FFR}_{\mathrm{MC}}$ when compared with $\mathrm{FFR}_{\mathrm{PW}}$ was $18 \%$ (figure 7). For physiologically intermediate lesions, when $\mathrm{FFR}_{\mathrm{PW}}$ falls in between 0.60 and 0.90 , the rate of reclassification increased to $23 \%$. In practice, this means that in one out of every five lesions interrogated by $\mathrm{FFR}_{\mathrm{MC}}$, physicians would face opposite guidance on revascularisation. ${ }^{1415}$ This high rate of disagreement in treatment guidance means that the extensive validation supporting FFR use with PW may not be directly extrapolated to MC. ${ }^{16}{ }^{17}$ Particularly, if all lesions with FFR $_{\mathrm{MC}} \leq 0.80$ were to be offered revascularisation, this would result in an increased rate of stenting when compared with $\mathrm{FFR}_{\mathrm{PW}}$ (15\% of total lesions). This could potentially increase procedure-related morbidity, as well as costs, ${ }^{18}$ without necessarily improving patients' symptoms or reducing ischaemia-related events.

\section{Interaction with lesion severity}

Our findings indicate that, for stenosis with lower FFR values, the bias in $\mathrm{FFR}_{\mathrm{MC}}$ readings compared with $\mathrm{FFR}_{\mathrm{PW}}$ is greater. One possible explanation for this is that the proportional effect of the size of the MC is greater for narrower lesions. This is in keeping with previous studies, ${ }^{35}$ which observed that the increased crossing profile of the MC might lead to a greater influence on numerical values when the ratio of its profile area to the mean lumen area was greater. The importance of device bulk on FFR values had been established previously in the case of fluid-filled catheters and 'buddy' wires. ${ }^{19} 20$ Figure 8 schematically demonstrate how MC profile interacts with coronary stenosis geometry and artificially yields lower FFR values. The MC occupies a larger proportional area at the level of the lesion. Although the maximum diameter of the device is 0.028 inches, at the level of the lesion, its cross-sectional area is greater than that of the $\mathrm{PW}$. In this scenario, the MC itself impedes antegrade flow resulting in a lower FFR value. This might explain the comparatively greater bias for lower FFR values measured with MC as compared with PW in more severe stenoses. The MC has been shown in one study to increase stenosis resistance, which supports the concept that it interferes with lesion haemodynamics. ${ }^{5}$

\section{No reduction in signal drift}

This study shows that there is no clinically significant difference in levels of drift between MC and PW. Both studies without significant outliers reported a difference of only 0.01 FFR units (table 3). Sensor drift is an important source of error during physiological assessment and it is generally recommended that measurements should be repeated when drift is greater than 


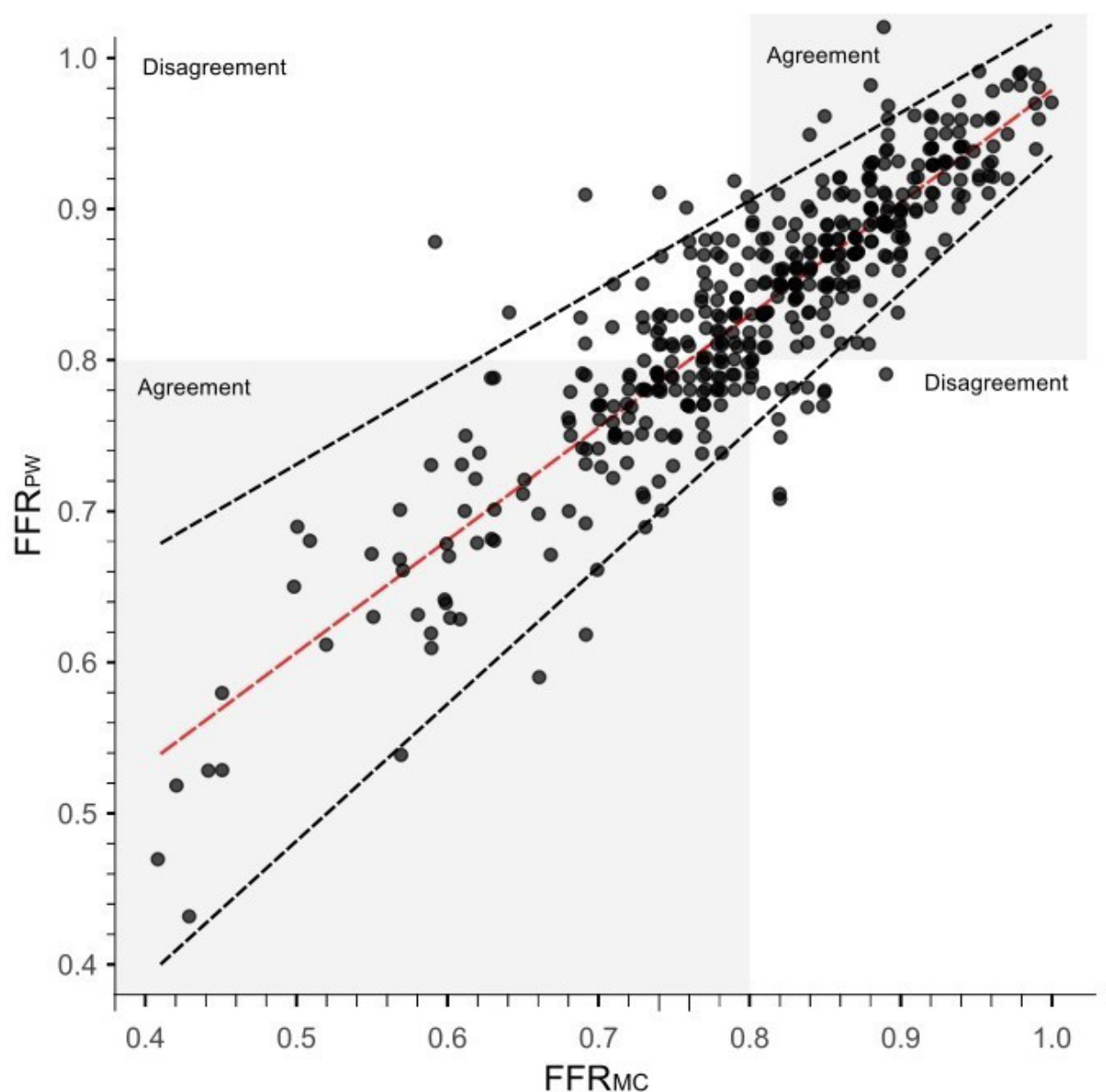

Figure 6 Scatter plot of microcatheter vs pressure wire FFR values for all lesions. The quadrants show regions of agreement and disagreement, according to the established clinical FFR cut-off of $\leq 0.80$. The dashed black line shows a regression of the bias. If a physician records a given microcatheter FFR value, they can be $95 \%$ confident that the corresponding pressure wire FFR value would lie within the black dashed lines. Note the predominant distribution of dots in the lower right quadrant, which represent lesions reclassified from negative to positive by the microcatheter (false positives). We provide an online appendix where readers can visualise the possible pressure wire FFR results for any given microcatheter FFR. FFR, fractional flow reserve.

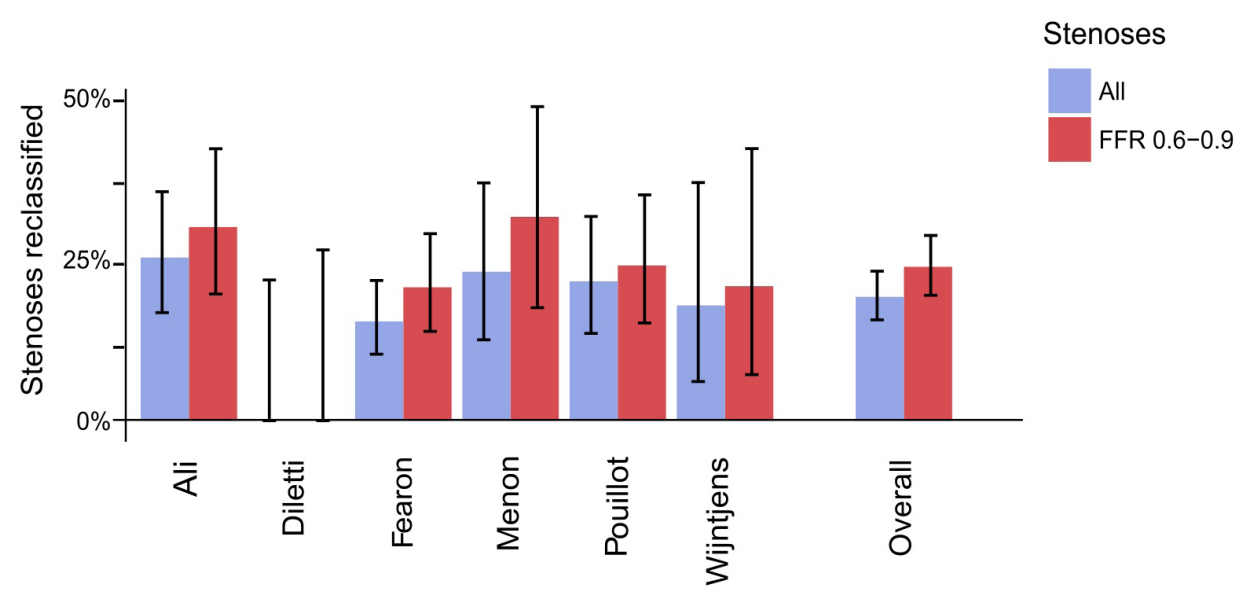

Figure 7 Reclassification of stenoses by microcatheter FFR, using pressure wire FFR as a reference comparison and a significance cut-off of $\leq 0.80$. Error bars show SD of percentage of stenoses that were reclassified. in one trial (1) there was no lesion reclassification (here displayed by bars of zero height). FFR, fractional flow reserve. 
Table 2 Signal drift reported by the studies.

\begin{tabular}{llllll}
\hline Study lead author & $\begin{array}{l}\text { Mean drift from } \\
\text { pressure wire }\end{array}$ & SD & $\begin{array}{l}\text { Mean drift from } \\
\text { microcatheter }\end{array}$ & SD & Reported P value \\
\hline Ali & 0.01 & 0.03 & 0.01 & 0.01 & 0.38 \\
Fearon & 0.015 & 0.017 & 0.014 & 0.012 & 0.66 \\
Menon & 0.06 & 0.02 & 0.02 & 0.02 & 0.014 \\
Wijntjens & $3.4 \mathrm{~mm} \mathrm{Hg}$ & $1.8 \mathrm{~mm} \mathrm{Hg}$ & $2.3 \mathrm{~mm} \mathrm{Hg}$ & $1.5 \mathrm{~mm} \mathrm{Hg}$ & 0.07 \\
\hline
\end{tabular}

One study ${ }^{4}$ found a significantly higher mean drift with $\mathrm{FFR}_{\mathrm{PW}}$ than $\mathrm{FFR}_{\mathrm{MC}}$. In this study, the mean drift was driven by three unusually large PW drift values of $6.5 \mathrm{~mm} \mathrm{Hg}, 4.0 \mathrm{~mm} \mathrm{Hg}$ and $3.4 \mathrm{~mm} \mathrm{Hg}$. All drift values are reported as FFR units except ${ }^{5}$ reported as change in distal pressure ( $\mathrm{mm} \mathrm{Hg}$ ).

$\mathrm{FFR}_{\mathrm{MC}}$, microcatheter fractional flow reserve; $\mathrm{FFR}_{\mathrm{PW}}$, pressure wire fractional flow reserve; $\mathrm{PW}$, pressure wire.

$\pm 0.02 .^{2}{ }^{21}$ Because the Navvus catheter contains an optical sensor rather than the piezo-resistive sensor used in standard PW, it emerged with great expectations for signal drift reduction. ${ }^{4}$ While across the four studies which provided mean drift values, drift was lower with $\mathrm{FFR}_{\mathrm{MC}}$ than $\mathrm{FFR}_{\mathrm{PW}}$ the difference was driven by a single study, that reported a mean drift of $6 \mathrm{~mm}$ $\mathrm{Hg}$ with $\mathrm{FFR}_{\mathrm{PW}}$, a value almost twice as large as seen with other studies.

\section{Device failure}

The theoretical benefit of the MC offering increased ease of use (because it can be passed over standard intracoronary guidewires) is not supported by our study. In fact, the studies included in our analysis showed the opposite: higher levels of device failure with the MC (overall $7.1 \%$ vs $2 \%$ for pressure guidewires). It is likely that, in practice, anatomies with increased tortuosity or calcification which are often difficult to cross with PW would also offer the same resistance for a bulkier overthe-wire MC system.

\section{Implications for clinicians}

Technological developments such as the Navvus microcatheter system can lead to increased use of coronary physiology and improve on the known limitations of angiography. Therefore, if clinicians prefer to use coronary workhorse wires routinely and measure FFR with

Table 3 Rate of device failure reported in each study.

\begin{tabular}{llc}
\hline Study lead author & $\begin{array}{l}\text { Pressure wire } \\
\text { failure (\%) }\end{array}$ & $\begin{array}{l}\text { Microcatheter } \\
\text { failure (\%) }\end{array}$ \\
\hline Menon & $10(6 / 58)$ & $2(1 / 58)$ \\
Ali & $0(0 / 96)$ & $5(5 / 96)$ \\
Wijntjens & $0(0 / 32)$ & $6(2 / 32)$ \\
Fearon & $0(0 / 223)$ & $6.2(13 / 223)$ \\
Pouillot & $2(2 / 123)$ & $12(15 / 123)$ \\
Overall & $2(8 / 519)$ & $7.1(32 / 519)$ \\
\hline
\end{tabular}

The overall weighted mean rate of device failure is higher for microcatheters than pressure wires.

$\mathrm{FFR}_{\mathrm{MC}}$, microcatheter fractional flow reserve; $\mathrm{FFR}_{\mathrm{PW}}$, pressure wire fractional flow reserve; PW, pressure wire. microcatheters instead of using anatomical guidance, they should remain encouraged, providing that $\mathrm{FFR}_{\mathrm{MC}}$ values are interpreted with caution.

Our findings highlight important practical differences between MC and PW FFR systems. First, because of the -0.029 numerical differences between methods and a relatively high rate of lesion reclassification, guideline recommendations which apply to $\mathrm{FFR}_{\mathrm{PW}}$ should not be extrapolated universally to $\mathrm{FFR}_{\mathrm{MC}}$ when FFR values are of intermediate severity. For instance, a physician who obtains a $\mathrm{FFR}_{\mathrm{MC}}$ of 0.70 might expect, in $95 \%$ of cases, to obtain a $\mathrm{FFR}_{\mathrm{PW}}$ of between 0.66 and 0.85 . Similarly, a $\mathrm{FFR}_{\mathrm{MC}}$ of 0.75 would be consistent with $\mathrm{FFR}_{\mathrm{PW}}$ values that ranged from 0.71 to 0.88 and a $\mathrm{FFR}_{\mathrm{MC}}$ of 0.80 would be consistent with $\mathrm{FFR}_{\mathrm{PW}}$ values that ranged from 0.75 to 0.91 (figure 6 and online supplementary appendix 1).

Second, physicians and healthcare systems should be aware that an increased rate of stent implantation could potentially result from the routine use of $\mathrm{FFR}_{\mathrm{MC}}$ and a rigid 0.80 cut-off interpretation. This could lead to

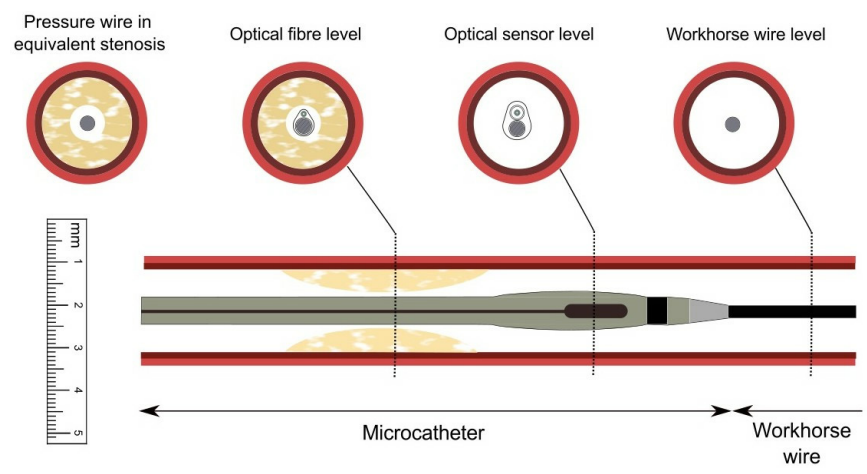

Figure 8 The impact of device cross-sectional area on vessel haemodynamics. Scalar image illustrating the cross sections of the device and the wire on which it is mounted at three different levels: the optical cable level within the lesion: the optical sensor level beyond the lesion and the workhorse wire alone beyond the lesion. Diameter stenosis at optical fibre level is $57 \%$. Area stenosis is $81 \%$. Although the maximum diameter of the device is 0.028 inches, at the level of the lesion, its cross-sectional area is more than twice that of the guidewire $\left(0.25 \mathrm{~mm}^{2}\right.$ vs $\left.0.10 \mathrm{~mm}^{2}\right)$. In this scenario, the microcatheter itself impedes antegrade flow with a resultant lowering of the FFR value. 
increased costs and the known consequences of unnecessary stent implantation. ${ }^{18}$

\section{Study limitations}

All of the studies included were open label observational studies, which increases the risk of bias. These studies were not performed with uniform comparator wire technology and therefore the MC was being assessed against a heterogeneous group of alternative technologies. One study used the Philips Volcano Combowire which is not used in routine clinical practice,${ }^{5}$ but has the same profile (0.014 inches).

Our analysis was not performed with the original data from each study. We, however, used a reproducible and well-validated methodology ${ }^{10}$ to extract each data point from each study, which still permitted a lesion-level analysis. This method provides a nearly identical approximation of the individual data points and resulted in an overall equal mean and SD reported by each study.

\section{CONCLUSIONS}

Compared with standard pressure guidewires, currently available MC technology (Navvus Microcatheter System) introduces a systematic bias to FFR, leading to lower values and a significant rate of lesion reclassification. Microcatheter FFR is not associated with a meaningful reduction in signal drift and demonstrate a higher rate of device failure. Pressure guidewires should, therefore, remain the reference standard for physiological lesion assessment.

Contributors HS, MSS, RP: design of the work. HS, MSS, AV, RP: data acquisition, interpretation and analysis. HS, MSS, AV, CK, CC, YA, JH, SS, RAL, SN, DC, JD, JM, DF, RP: critical review. All authors reviewed and approved the final manuscript.

Funding The authors are grateful for the infrastructural support from the National Institute of Health Research (NIHR) Biomedical Research Centre based at Imperial College Healthcare NHS Trust and Imperial College London. Drs Shun-Shin, Davies and Francis are supported by grants from The British Heart Foundation (FS/14/27/30752, FS 04, 079, FS 05/006). Dr Cook is supported by a grant from The Medical Research Council (MR/M018369/1). Dr Petraco is supported by a National Institute for Health Research clinical lectureship grant (CL-2015-21-001).

Competing interests Drs Cook, Al-Lamee and Nijjer have conducted teaching sessions supported by Volcano Corporation. Dr Petraco is a consultant for Philips Volcano. Dr Davies is a consultant for and has received research funding from Philips Volcano. Dr Sen has attended and conducted teaching sessions supported by Volcano Corporation, St. Jude Medical, Medtronic, Pfizer and AstraZeneca. Dr Chamie has acted as a consultant to Abott Vascular inc. All other authors have reported that they have no relationships relevant to the contents of this paper to disclose.

Patient consent for publication Not required.

Provenance and peer review Not commissioned; externally peer reviewed. Data sharing statement No additional data are available.

Open access This is an open access article distributed in accordance with the Creative Commons Attribution Non Commercial (CC BY-NC 4.0) license, which permits others to distribute, remix, adapt, build upon this work non-commercially, and license their derivative works on different terms, provided the original work is properly cited, appropriate credit is given, any changes made indicated, and the use is non-commercial. See: http://creativecommons.org/licenses/by-nc/4.0/.

\section{REFERENCES}

1. Diletti R, Van Mieghem NM, Valgimigli M, et al. Rapid exchange ultra-thin microcatheter using fibre-optic sensing technology for measurement of intracoronary fractional flow reserve. Eurolntervention2015;11:428-32.

2. Cook CM, Ahmad Y, Shun-Shin MJ, et al. Quantification of the effect of pressure wire drift on the diagnostic performance of fractional flow reserve, instantaneous Wave-Free ratio, and Whole-Cycle $\mathrm{Pd} / \mathrm{Pa}$. Circ Cardiovasc Interv 2016;9:e002988.

3. Pouillot C, Fournier S, Glasenapp J, et al. Pressure wire versus microcatheter for FFR measurement: a head-to-head comparison. Eurolntervention 2018;13:e1850-6.

4. Menon M, Jaffe W, Watson T, et al. Assessment of coronary fractional flow reserve using a monorail pressure catheter: the firstin-human ACCESS-NZ trial. Eurolntervention 2015;11:257-63.

5. Wijntjens GWM, van de Hoef TP, Kraak RP, et al. The impact study (influence of Sensor-Equipped Microcatheters on coronary hemodynamics and the accuracy of physiological indices of functional stenosis severity). Circ Cardiovasc Interv 2016;9.

6. Fearon WF, Chambers JW, Seto AH, et al. ACIST-FFR study (assessment of Catheter-Based interrogation and standard techniques for fractional flow reserve measurement). Circ Cardiovasc Interv 2017;10.

7. Ali ZA, Parviz Y, Brinkman M, et al. Pressure wire compared to microcatheter sensing for coronary fractional flow reserve: the perform study. Eurolntervention 2018;14:e459-66.

8. Moher D, Liberati A. Preferred reporting items for systematic reviews and meta-analyses: the PRISMA statement. Ann Intern Med 2009;151:264-9.

9. Whiting PFet al. QUADAS-2: a revised tool for the quality assessment of diagnostic accuracy studies. Ann Intern Med 2011;155:529-36.

10. Cook CM, Petraco R, Shun-Shin MJ, et al. Diagnostic Accuracy of Computed Tomography-Derived Fractional Flow Reserve : A Systematic Review. JAMA Cardiol 2017;2:803-10.

11. Bland JM, Altman DG. Statistical methods for assessing agreement between two methods of clinical measurement. Lancet 1986;1:307-10.

12. Bland JM, Altman DG. Measuring agreement in method comparison studies. Stat Methods Med Res 1999;8:135-60.

13. R Development Core Team. R, A Language and Environment for Statistical Computing. New Zealand: University of Auckland, 2017.

14. Fihn SD, Blankenship JC, Alexander KP, et al. ACC/AHA/AATS/ PCNA/SCAI/STS focused update of the guideline for the diagnosis and management of patients with stable ischemic heart disease: a report of the American College of Cardiology/American Heart Association Task Force on practice guidelines, and the American Association for thoracic surgery, preventive cardiovascular nurses association, Society for cardiovascular angiography and interventions, and Society of thoracic surgeons. Circulation 2014;130:1749-67.

15. Authors/Task Force members, Windecker S, Kolh P, et al. 2014 ESC/EACTS Guidelines on myocardial revascularization: The Task Force on Myocardial Revascularization of the European Society of Cardiology (ESC) and the European Association for Cardio-Thoracic Surgery (EACTS)Developed with the special contribution of the European Association of Percutaneous Cardiovascular Interventions (EAPCl). Eur Heart J 2014;35:2541-619.

16. De Bruyne B, Pijls NHJ, Kalesan B, et al. Fractional flow ReserveGuided $\mathrm{PCl}$ versus medical therapy in stable coronary disease. $N$ Engl J Med 2012;367:991-1001.

17. Tonino PAL, De Bruyne B, Pijls NHJ, et al. Fractional flow reserve versus angiography for guiding percutaneous coronary intervention. N Engl J Med 2009;360:213-24.

18. Fearon WF, Bornschein B, Tonino PAL, et al. Economic evaluation of fractional flow Reserve-Guided percutaneous coronary intervention in patients with multivessel disease. Circulation 2010;122:2545-50.

19. Serruys PW, Wijns W, Reiber JH, et al. Values and limitations of transstenotic pressure gradients measured during percutaneous coronary angioplasty. Herz 1985;10:337-42.

20. Verberne HJ, Meuwissen M, Chamuleau SA, et al. Effect of simultaneous intracoronary guidewires on the predictive accuracy of functional parameters of coronary lesion severity. Am J Physiol Heart Circ Physiol 2007;292:H2349-H2355.

21. Jeremias A, Maehara A, Généreux P, et al. Multicenter core laboratory comparison of the instantaneous Wave-Free ratio and resting $\mathrm{p} d / \mathrm{P}$ A with fractional flow reserve. J Am Coll Cardiol 2014;63:1253-61. 


\section{Correction: Fractional flow reserve derived from microcatheters versus standard pressure wires: a stenosis- level meta-analysis}

Seligman H, Shun-Shin MJ, Vasireddy A, et al. Fractional flow reserve derived from microcatheters versus standard pressure wires: a stenosis-level meta-analysis. Open Heart 2019;6:e00971. doi: 10.1136/openhrt-2018-000971

The license type of the paper has changed from CC BY-NC to CC BY.

Open access This is an open access article distributed in accordance with the Creative Commons Attribution 4.0 Unported (CC BY 4.0) license, which permits others to copy, redistribute, remix, transform and build upon this work for any purpose, provided the original work is properly cited, a link to the licence is given, and indication of whether changes were made. See: https:// creativecommons.org/licenses/by/4.0/.

(C) Author(s) (or their employer(s)) 2019. Re-use permitted under CC BY. Published by BMJ.

Open Heart 2019;6:e000971corr1. doi:10.1136/openhrt-2018-000971 corr1

A) Check for updates 